\title{
Digitalis-Induced Increase in Aortic Regurgitation and the Contrasting Effects of Glucagon in the Sedated Dog
}

\author{
BARRY E. Hopkins and Roger R. TAYLOR with the technical assistance of \\ Peter Burrows \\ From the Department of Medicine, University of Western Australia, and the \\ Research and Experimental Unit and Cardiology Departments of Royal Perth \\ Hospital, Perth, Western Australia
}

A в S T R A C T The hemodynamic and phasic ascending aortic flow changes induced by acetylstrophanthidin and glucagon were studied in closed-chest sedated dogs with aortic regurgitation. While the positive inotropic effect of both agents was reflected in an increase in peak rate of rise of left ventricular pressure, acetylstrophanthidin increased aortic regurgitation, while glucagon decreased it. With the former, left ventricular end-diastolic pressure rose from $20 \pm 6$ to $27 \pm 6 \mathrm{~mm} \mathrm{Hg}(P<0.005)$, but fell from $18 \pm 4$ to $11 \pm 3 \mathrm{~mm} \mathrm{Hg}(P<0.001)$ with glucagon. Acetylstrophanthidin increased systemic vascular resistance, aortic diastolic pressure, and diastolic regurgitant flow rate, and, heart rate and the duration of regurgitation per beat and per minute being unchanged, regurgitant flow per beat increased $32 \pm 15 \%$ $(P<0.001)$. Glucagon decreased regurgitant flow per beat $27 \pm 14 \% \quad(P<0.001)$ because of abbreviation of diastole associated with tachycardia, and because of reduction in regurgitant flow rate. Despite tachycardia, the duration of regurgitation per minute was unchanged, and the small fall in regurgitant blood flow per minute was not significant, but this pertained in the face of $47 \%$ increase in effective cardiac output $(P<0.001)$. In contrast, acetylstrophanthidin increased regurgitant flow per minute $28 \pm 14 \%(P<0.001)$ without change in effective cardiac output. The increase in cardiac contractility, tachycardia, and systemic vasodilatation induced by glucagon preferentially enhanced forward blood flow, which led to reduction in left ventricular volume overload, while it increased cardiac output. Contrarily, acetylstrophanthidin increased aortic regurgitation and, despite its inotropic effect, increased left ventricular volume overload without an increase in cardiac output.

Received for publication 25 April 1973 and in revised form 16 November 1973.

\section{INTRODUCTION}

The successful use of digitalis glycosides in the treatment of low output cardiac failure is mainly attributed to the positive inotropic effect of digitalis glycosides and the accompanying increase in cardiac output and reduction of elevated ventricular diastolic pressure $(1,2)$. Under some circumstances, however, the glycosides do not exert an obviously beneficial effect on the circulation, e.g., acetylstrophanthidin in experimental myocardial infarction (3). Similarly, clinical observation and hemodynamic measurements have indicated that digitalis preparations are often of little value in clinical acute myocardial infarction (4). Pre-existing circulatory failure has even been observed to be occasionally aggravated by digoxin in hypertensive and ischemic heart disease (5) and by ouabain in cardiogenic shock (6).

In aortic regurgitation, Corrigan asserted in 1832, "patients under its [digitalis'] exhibition are always worse" (7). While Corrigan attributed his observation of a harmful effect of digitalis in patients with aortic regurgitation to induced bradycardia, Stewart later postulated that, due to their vasoconstrictor effect, digitalis glycosides would increase aortic regurgitation (8). That digitalis increases systemic vascular resistance in animals $(9,10)$ and in man $(11,12)$ is now well documented, although the response may be attenuated or reversed in the presence of cardiac failure $(10,12,13)$.

The effects of digitalis glycosides on aortic regurgitation are, then, of great interest, especially since we have recently demonstrated an increase in aortic regurgitation with the positive inotropic and pressor agent, norepinephrine (14), and in view of the widespread use of the cardiac glycosides. The present study represents one approach to this question. The short-acting cardiac glycoside, acetylstrophanthidin, was administered to sedated 
closed-chest dogs in which aortic regurgitation had been recently induced and a flow transducer implanted on the ascending aorta. Since acetylstrophanthidin was found to increase aortic regurgitation with resultant effects on the circulation, the hemodynamic effects of the glycoside in normal animals were also studied for comparison. Further comparison was made with the effects of glucagon on aortic regurgitation. Glucagon was selected because of its known positive chronotropic and vasodepressor, as well as inotropic, properties, and because it has been extensively examined for use in the treatment of severe heart disease without documentation of its effect on aortic regurgitation.

\section{METHODS}

Mongrel dogs weighing 18.6-25.9 kg were anesthetized with intravenous sodium pentobarbital $(20-30 \mathrm{mg} / \mathrm{kg})$ and ventilated with nitrous oxide and oxygen (1:1). After median sternotomy, the pericardium was opened longitudinally and sutured to the left chest wall to facilitate later percutaneous left ventricular puncture. Through an anterior aortotomy a metal punch assembly was advanced to the noncoronary cusp of the aortic valve (15). After piercing the cusp, the trocar handle was simultaneously rotated and retracted, thus producing a circular defect in the cusp by the cutting action of the trocar head on the body of the cannula. With inflow occlusion of less than 10-s duration, the punch was removed and, over a nonocclusive vascular clamp, the aortotomy was closed by using $5 / 0$ cardiovascular silk. A closely fitting electromagnetic flow transducer (15-18-mm diam) was placed around the aorta and packed with oxycellulose gauze, care being taken to avoid aortic constriction. The flow transducer leads were implanted subcutaneously in the left axilla. Normal dogs were similarly prepared, except for aortotomy and induction of regurgitation.

Between 5 and 11 days after surgery, the animals were sedated with intramuscular morphine $(3 \mathrm{mg} / \mathrm{kg})$, promazine $(1.5 \mathrm{mg} / \mathrm{kg})$, and promethazine $(1.5 \mathrm{mg} / \mathrm{kg})$. Lidocaine $0.5 \%$ was used as a local analgesic for catheter insertions.

Left ventricular pressure (LVP) ${ }^{1}$ was obtained by using a $10-\mathrm{cm}$ stiff polyethylene cannula, which was inserted percutaneously on a no. 19 spinal needle, attached directly to a pressure transducer. Central aortic pressure (AP) was measured through a catheter passed from a femoral artery, and intrapleural pressure (IPP) through a self-retaining Foley catheter. LVP and AP were measured with Statham P23 Db transducers, and IPP with a Statham 23 AA transducer (Statham Instruments, Inc., Oxnard, Calif.). The first time derivative of LVP $(\mathrm{LV} \mathrm{d} p / \mathrm{d} t)$ was obtained with an $\mathrm{R}-\mathrm{C}$ differentating circuit.

Phasic aortic flow recordings were obtained by connecting the flow probe terminals, previously implanted subcutaneously, to a pulsed logic meter (Biotronex, Inc., Silver Spring, Md., model BL-610-2A). Electronic zero was checked after each flow recording, and in vivo absolute aortic flow zero was obtained twice in each experiment

${ }^{1}$ Abbreviations used in this paper: AP, aortic pressure; IPP, intrapleural pressure; $\mathrm{LV} \mathrm{d} p / \mathrm{d} t$, peak rate of rise of left ventricular pressure; LVEDP, left ventricular enddiastolic pressure; LVP, left ventricular pressure; RF, regurgitant fraction; RV, regurgitant volume; TSV, total volume ejected by the left ventricle per beat. by inducing circulatory arrest with the intraventricular injection of acetylcholine. Spontaneous electrical and mechanical activity returned within $8 \mathrm{~s}$ on all occasions and hemodynamic and flow parameters returned to preinjection values within $10 \mathrm{~min}$ of the injection. Cardiac output was measured in duplicate by left ventricular injection, and aortic sampling of indocyanine green dye by using a Gilford densitometer (Gilford Instrument Laboratories, Inc., Oberlin, Ohio, model 103-IR) and Texas Instruments recorder (Texas Instruments, Inc., Digital Systems Div., Houston, Tex., model PRR-IM-A25-Q). The standard deviation of cardiac output determination by the method of paired measurements was $0.2 \mathrm{liter} / \mathrm{min}$ ( $8 \%$ of measurement). To calibrate the electromagnetic flow recording, mean stroke volume, derived from the cardiac output determination, was equated with the mean time integral of the net forward flow in four representative cardiac cycles recorded during inscription of the dye dilution curves. The standard deviation of this calibration by the method of paired measurements was $9 \%$ of the calibration factor. Pressures, aortic flow, and electrocardiogram were recorded on an eight channel direct writing recorder (Hewlett-Packard Co., Palo Alto, Calif., model 7718A).

Heart rate and other hemodynamic parameters varied with the respiratory cycle (16). The value assigned to each parameter is, therefore, its mean over a representative respiratory cycle. Transmural left ventricular end-diastolic pressure (LVEDP) was obtained by subtracting IPP from the measured end-diastolic pressure. Regurgitant fraction (RF) was calculated by dividing the regurgitant volume $(R V)$ by the total volume ejected from the left ventricle per beat (TSV) : RF $=R V / T S V$. The measurement designated as early diastolic regurgitant flow rate was made an arbitrary $60 \mathrm{~ms}$ after the onset of regurgitation as seen on the recording of flow. That which was designated as late diastolic flow rate was measured $20 \mathrm{~ms}$ before regurgitation ceased. The regurgitant period (or duration of diastole in normal dogs) was measured between the points of intersection of the flow trace with the zero flow line and is expressed in millisec/beat and $\mathrm{sec} / \mathrm{min}$.

Glucagon solution for intravenous injection was prepared immediately before use by dissolving $1 \mathrm{mg}$ glucagon USP in $10 \mathrm{ml}$ of the diluent provided. Six animals received $40 \mu \mathrm{g} / \mathrm{kg}$ body weight and two received $20 \mu \mathrm{g} / \mathrm{kg}$ over 1 min through a femoral vein catheter. Recordings were made at the end of injection and 2, 3, 5, and $10 \mathrm{~min}$ later.

Acetylstrophanthidin, $20 \mu \mathrm{g} / \mathrm{kg}$, prepared in solution with normal saline, was infused over 2 min into eight animals with aortic regurgitation and into seven normals. Four of the animals with aortic regurgitation had received glucagon $20 \mathrm{~min}$ before, after which hemodynamic parameters had returned to their control values. Recordings were made before and at the end of injection and 2, 3, 5, and 10 min later. The hemodynamic effects of acetylstrophanthidin are also rapid in onset, being maximum within $5 \mathrm{~min}$.

The significance of changes induced by the interventions were evaluated by using Student's paired $t$ test, and the differences between group means with Student's $t$ test. That is, the mean percentage change in each parameter induced by intervention and the variability of that change were obtained from the changes induced in individual animals. The mean percentage changes detailed in the tables do not, therefore, necessarily coincide exactly with the changes that would be obtained from using the pooled mean values of the parameters before and after intervention. Similarly, the figures for regurgitant fraction and 
TABLE I

Hemodynamic Changes Induced by Acetylstrophanthidin

\begin{tabular}{|c|c|c|c|c|c|c|c|c|c|}
\hline & \multirow{2}{*}{$\begin{array}{l}\text { Heart } \\
\text { rate }\end{array}$} & \multirow[b]{2}{*}{ LVEDP } & \multirow[b]{2}{*}{$L V \mathrm{~d} P / \mathrm{d} t$} & \multirow{2}{*}{$\begin{array}{c}\text { Peak } \\
\text { systolic } \\
\text { flow rate }\end{array}$} & \multicolumn{3}{|c|}{ Aortic pressure } & \multirow{2}{*}{$\begin{array}{l}\text { Cardiac } \\
\text { index }\end{array}$} & \multirow{2}{*}{$\begin{array}{l}\text { Systemic } \\
\text { vascular } \\
\text { resistance }\end{array}$} \\
\hline & & & & & Systolic & Diastolic & Mean & & \\
\hline & beats/min & $m m \mathrm{Hg}$ & $m m ~ H g / s$ & $\mathrm{ml} / \mathrm{s}$ & & $m m \mathrm{Hg}$ & & $\mathrm{ml} / \mathrm{kg} / \mathrm{min}$ & $\operatorname{dyn} \mathrm{cm} \mathrm{s}^{-5}$ \\
\hline \multicolumn{10}{|c|}{ Aortic regurgitation $(n=8)$} \\
\hline Control & 103 & 20.2 & 3,955 & $446 \|$ & $132 \|$ & $57 \S$ & $82 \|$ & 108 & 2,853 \\
\hline Acetylstrophanthidin* & 99 & 26.6 & 5,122 & 473 & 162 & 69 & 100 & 105 & 3,673 \\
\hline $\begin{array}{l}\% \text { change } \ddagger \\
\text { Significance of }\end{array}$ & $-2 \pm 8$ & $+36 \pm 21$ ा & $+30 \pm 6$ & $+11 \pm 3$ & $+24 \pm 12$ & $+23 \pm 12$ & $+23 \pm 10$ & $-4 \pm 17$ & $+31 \pm 26$ \\
\hline change, $P$ & NS & $<0.005$ & $<0.001$ & $<0.001$ & $<0.001$ & $<0.001$ & $<0.001$ & NS & $<0.02$ \\
\hline Normal $(n=7)$ & & & & & & & & - & \\
\hline Control & 104 & 6.7 & 3,451 & 261 & 125 & 78 & 93 & 105 & 3,737 \\
\hline Acetylstrophanthidin* & 98 & 7.0 & 4,483 & 292 & 145 & 88 & 107 & 107 & 4.431 \\
\hline $\begin{array}{l}\% \text { change } \neq \\
\text { Significance of }\end{array}$ & $-7 \pm 16$ & $+1 \pm 17$ & $+29 \pm 10$ & $+14 \pm 7$ & $+16 \pm 7$ & $+13 \pm 5$ & $+15 \pm 12$ & $-1 \pm 11$ & $+17 \pm 19$ \\
\hline change, $P$ & NS & NS & $<0.001$ & $<0.005$ & $<0.001$ & $<0.001$ & $<0.02$ & NS & NS \\
\hline
\end{tabular}

* Measurements made at time of maximal effect of acetylstrophanthidin.

$\ddagger$ Values are mean $\pm 1 \mathrm{SD}$. Variability of other mean values and data from individual animals are available from authors on request.

\& || I Values significantly different from normal group: $\S(P<0.001)$; $\|(P<0.05) ;$ I $(P<0.005)$.

other derived variables quoted in the tables are not precisely the same as those which would be obtained from using pooled mean data also supplied in the tables.

\section{RESULTS}

All animals with aortic regurgitation had collapsing pulses and precordial diastolic murmurs. None had edema or significant pleural or pericardial fluid or adhesions. The normal animals and those with regurgitation were comparable with respect to body weight and left ventricular weight per kilogram body weight. Heart rate and systemic blood flow, i.e. cardiac output, were similar, but aortic diastolic and mean pressures were significantly lower in the animals with regurgitation, and aortic systolic pressure and LVEDP were significantly higher (Table I).

The changes induced by acetylstrophanthidin are presented in Tables I and II and those induced by glucagon in Tables III and IV. Mean values of the measured parameters before and at the time of peak effect of the interventions are tabulated, along with mean percentage changes, the variability of the changes, and the significance of the changes induced. Mean changes were compiled for all eight animals receiving glucagon, since the changes in the two receiving $20 \mu \mathrm{g} / \mathrm{kg}$ were not different from those in the six given $40 \mu \mathrm{g} / \mathrm{kg}$. No temporal dissociation of the various effects produced by either intervention could be discerned, which is particularly

TABLE II

Flow Changes with Acetylstrophanthidin

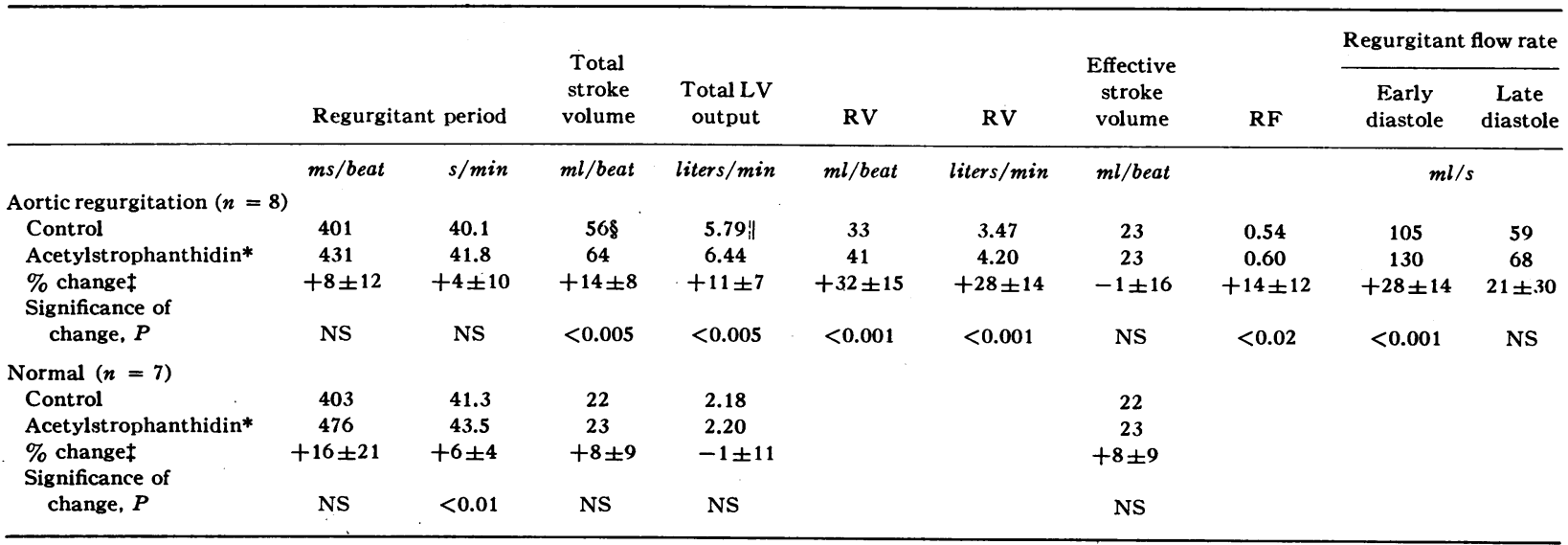

* Measurements made at time of maximal effect of acetylstrophanthidin.

$¥$ Values are mean $\pm 1 \mathrm{SD}$. Variability of other mean values and data from individual animals are available from the authors on request.

\& || Values significantly different from normal group; \& $(P<0.05)$; $\|(P<0.01)$. 
TABLE III

Hemodynamic Changes Induced by Glucagon

\begin{tabular}{|c|c|c|c|c|c|c|c|c|c|}
\hline & \multirow[b]{2}{*}{ Heart rate } & \multirow[b]{2}{*}{ LVEDP } & \multirow[b]{2}{*}{$\mathrm{LV} \mathrm{d} P / \mathrm{d} t$} & \multirow{2}{*}{$\begin{array}{c}\text { Peak } \\
\text { systolic } \\
\text { flow rate }\end{array}$} & \multicolumn{3}{|c|}{ Aortic pressure } & \multirow{2}{*}{$\begin{array}{c}\text { Cardiac } \\
\text { index }\end{array}$} & \multirow{2}{*}{$\begin{array}{c}\text { Systemic } \\
\text { vascular } \\
\text { resistance }\end{array}$} \\
\hline & & & & & Systolic & Diastolic & Mean & & \\
\hline & beats/min & $m m \mathrm{Hg}$ & $m m ~ H g / s$ & $m l / s$ & \multicolumn{3}{|c|}{$m m \mathrm{Hg}$} & $\mathrm{ml} / \mathrm{kg} / \min$ & $d y n \mathrm{~cm} \mathrm{~s}^{-\mathrm{s}}$ \\
\hline Control & 102 & 18.4 & 4.565 & 478 & 138 & 58 & 85 & 120 & 3,036 \\
\hline Glucagon* & 131 & 11.4 & 6,556 & 531 & 134 & 51 & 79 & 179 & 1,948 \\
\hline $\begin{array}{l}\% \text { changet } \\
\text { Significance }\end{array}$ & $+29 \pm 13$ & $-38 \pm 14$ & $+43 \pm 11$ & $+12 \pm 6$ & $-3 \pm 5$ & $-12 \pm 10$ & $-7 \pm 7$ & $+47 \pm 13$ & $-36 \pm 9$ \\
\hline of change, $P$ & $<0.001$ & $<0.001$ & $<0.001$ & $<0.001$ & NS & $<0.02$ & $<0.02$ & $<0.001$ & $<0.001$ \\
\hline
\end{tabular}

Aortic regurgitatant $(n=8)$.

* Measurements made at time of maximal effect of glucagon.

$\ddagger$ Values are mean \pm 1 SD. Variability of other mean values and data from individual animals are available from authors on request.

relevant to acetylstrophanthidin, since the vasopressor effect of other glycosides having a slower onset of action has been considered to preceed their positive inotropic effect $(5,9,11,17)$. Since all effects of both interventions were maximum within $10 \mathrm{~min}$, the period of observation was not extended further. Fig. 1 shows typical recordings from an animal with aortic regurgitation given acetylstrophanthidin, and Fig. 2, those from a normal animal; Fig. 3 illustrates the response to glucagon.

Both acetylstrophanthidin and glucagon increased peak rate of rise of left ventricular pressure $(\mathrm{LV} \mathrm{d} p / \mathrm{d} t)$ consistent with their known positive inotropic effect. Acetylstrophanthidin increased systemic vascular resistance by $31 \pm 26 \%(P<0.02)$ in animals with regurgitation, cardiac output, i.e., systemic blood flow and heart rate being unchanged (Table I). Glucagon decreased systemic vascular resistance $36 \pm 9 \% \quad(P<$ $0.001)$, while heart rate was increased $29 \pm 13 \%(P<$ $0.001)$, and cardiac output was increased $47 \pm 13 \%$ $(P<0.001)$. (Table III). While acetylstrophanthidin increased aortic regurgitation, glucagon decreased it.

Acetylstrophanthidin increased regurgitant volume per beat $32 \pm 15 \%(P<0.001)$, a process entirely attributable to increase in regurgitant flow rate, most marked in early diastole (Table II). Glucagon reduced RV per beat
$27 \pm 14 \%(P<0.001)$ because of reduction in the regurgitant period per beat associated with tachycardia and also because of reduction in regurgitant flow rate (Table IV). Regurgitant period per minute was unchanged by either intervention, since, although glucagon produced tachycardia, the duration of each systole was reduced. Hence, although the tachycardia and abbreviation of diastole induced by glucagon contributed to the reduction in $R V$ per beat, it did not influence $R V$ per minute. The small mean fall in the latter, induced by glucagon, was not significant. RV per minute did, however, remain constant or fall in response to glucagon in seven of the eight animáls in the face of an invariable large increase in both total left ventricular output per minute and in effective forward flow, i.e., cardiac output. Acetylstrophanthidin, on the other hand, produced a significant increase in RV per minute, while cardiac output was unaltered. RF increased, while it fell with glucagon.

With acetylstrophanthidin, effective stroke volume remained constant, but increase in RV per beat necessitated an increase in total stroke volume of $14 \pm 8 \%(P<$ 0.005 ). Alternatively, it can be said that acetylstrophanthidin increased total stroke volume, but this increase was entirely dissipated in greater RV. Conversely, the decrease in $\mathrm{RV}$ per beat with glucagon meant that, al-

TABLE IV

Flow Changes with Glucagon

\begin{tabular}{|c|c|c|c|c|c|c|c|c|c|c|}
\hline & \multirow{2}{*}{\multicolumn{2}{|c|}{ Regurgitant period }} & \multirow{3}{*}{$\begin{array}{c}\begin{array}{c}\text { Total } \\
\text { stroke } \\
\text { volume }\end{array} \\
\mathrm{ml} / \text { beat }\end{array}$} & \multirow{3}{*}{$\begin{array}{c}\begin{array}{c}\text { Total LV } \\
\text { output }\end{array} \\
\text { liters/min }\end{array}$} & \multirow{3}{*}{$\frac{\mathrm{RV}}{m l / b e a t}$} & \multirow{3}{*}{$\frac{\mathrm{RV}}{\text { liters } / \text { min }}$} & \multirow{3}{*}{$\begin{array}{c}\begin{array}{c}\text { Effective } \\
\text { stroke } \\
\text { volume }\end{array} \\
m l / \text { beat }\end{array}$} & \multirow{3}{*}{ RF } & \multicolumn{2}{|c|}{ Regurgitant flow rate } \\
\hline & & & & & & & & & $\begin{array}{c}\text { Early } \\
\text { diastole }\end{array}$ & $\begin{array}{c}\text { Late } \\
\text { diastole }\end{array}$ \\
\hline & $m s / b e a t$ & $s / \min$ & & & & & & & \multicolumn{2}{|c|}{$m l / s$} \\
\hline Control & 417 & 40.8 & 59 & 5.92 & 32 & 3.29 & 27 & 0.53 & 98 & 62 \\
\hline Glucagon* & 328 & 41.5 & 53 & 6.86 & 23 & 2.97 & 30 & 0.42 & 78 & 52 \\
\hline $\begin{array}{l}\text { \% change } \\
\text { Significance }\end{array}$ & $-21 \pm 6$ & $+2 \pm 8$ & $-10 \pm 8$ & $+17 \pm 11$ & $-27 \pm 14$ & $-6 \pm 21$ & $+13 \pm 11$ & $-20 \pm 13$ & $-20 \pm 15$ & $-16 \pm 15$ \\
\hline of change, $P$ & $<0.001$ & NS & $<0.005$ & $<0.005$ & $<0.001$ & NS & $<0.02$ & $<0.005$ & $<0.01$ & $<0.02$ \\
\hline
\end{tabular}

Aortic regurgitation $(n=8)$.

* Measurements made at time of maximal effect of glucagon.

‡ Values are mean \pm 1 SD. Variability of other mean values and data from individual animals are available from authors on request. 


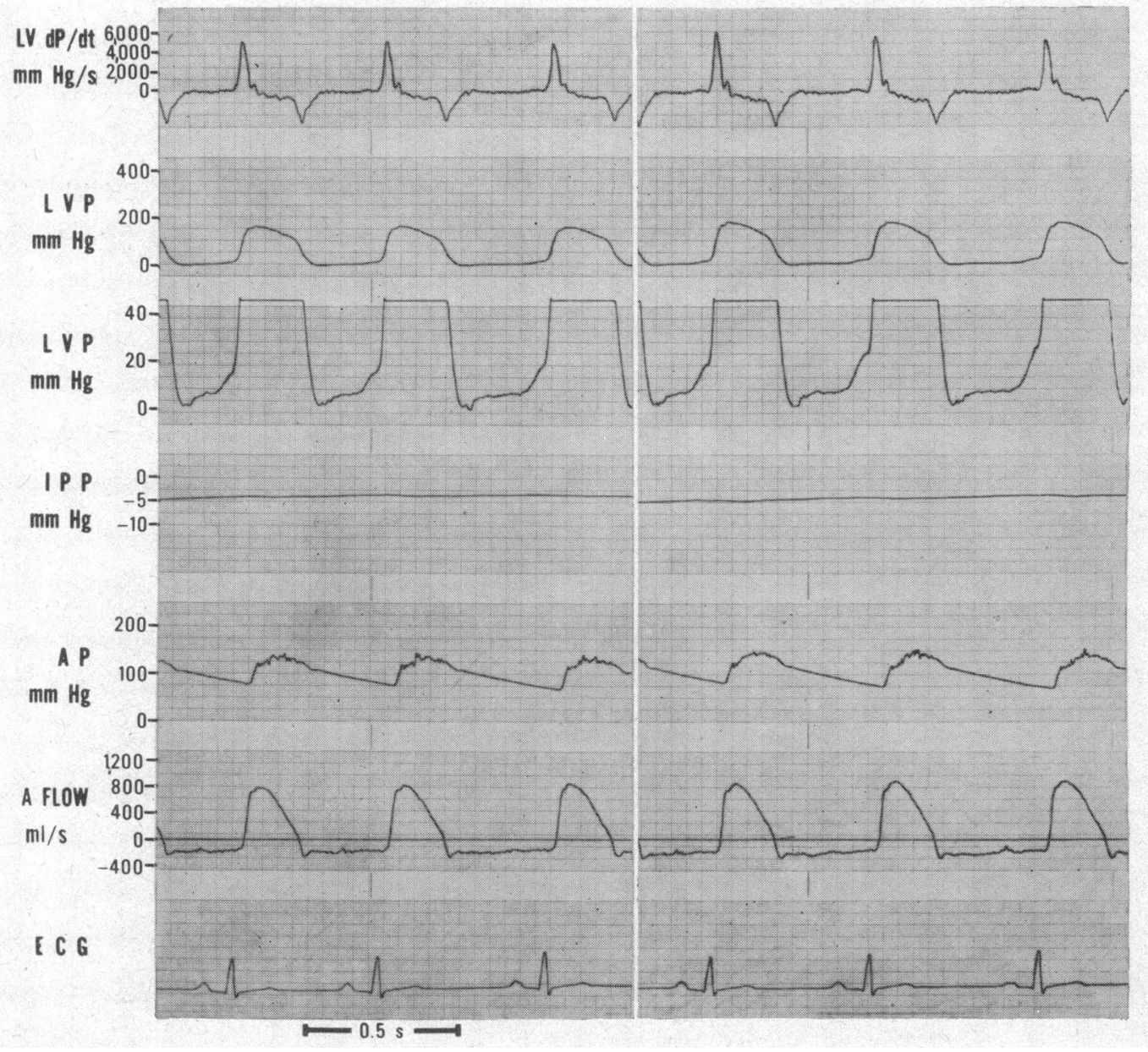

FIGURE 1 Recordings from an animal with aortic regurgitation in the control state (panel A) and after acetylstrophanthidin (panel B) in comparable expiratory phases of respiration. A Flow, ascending aortic blood flow; ECG, electrocardiogram. Although in this particular animal the increases in early diastolic regurgitant flow rate $(240 \rightarrow 265 \mathrm{ml} / \mathrm{s})$, in $\mathrm{RV}(73 \rightarrow 83 \mathrm{ml} /$ beat $)$, and in aortic pressure $(135 / 75 \rightarrow 145 / 75 \mathrm{~mm} \mathrm{Hg})$ were somewhat less than average, LVEDP increased $8 \mathrm{~mm} \mathrm{Hg}$. Paper speed $100 \mathrm{~mm} / \mathrm{s}$.

though total stroke volume fell $10 \pm 6 \%(P<0.005)$, effective stroke volume rose $13 \pm 11 \%(P<0.02)$.

LVEDP in animals with aortic regurgitation was increased from $20 \pm 9 \mathrm{~mm} \mathrm{Hg}$ to $27 \pm 6 \mathrm{~mm} \mathrm{Hg}(P<$ 0.005 ) by acetylstrophanthidin, but was lowered from $18 \pm 4 \mathrm{~mm} \mathrm{Hg}$ to $11 \pm 3 \mathrm{~mm} \mathrm{Hg}(P<0.001)$ by glucagon. The response of LVEDP in normal animals was also in contrast, being unchanged by acetylstrophanthidin. The latter difference presumably resulted because, although the other circulatory effects were of similar magnitude in animals with and without regurgitation, the left ventricle received additional volume loading only, of course, in those animals with aortic regurgitation.
In one animal, ouabain, $20 \mu \mathrm{g} / \mathrm{kg}$, was administered intravenously and Fig. 4 contrasts the effects of this with the effects of glucagon, $40 \mu \mathrm{g} / \mathrm{kg}$, given earlier. While the recordings show that glucagon decreased aortic regurgitant flow rate, aortic pressure, and LVEDP, ouabain increased all of these parameters.

\section{DISCUSSION}

The effect of digitalis glycosides and glucagon on aortic regurgitation has not been previously documented, although their general hemodynamic effects are well known (1-6; 9-13, 18-33). Both agents increased LV $\mathrm{d} p / \mathrm{d} t$ in a manner consistent with their direct positive 


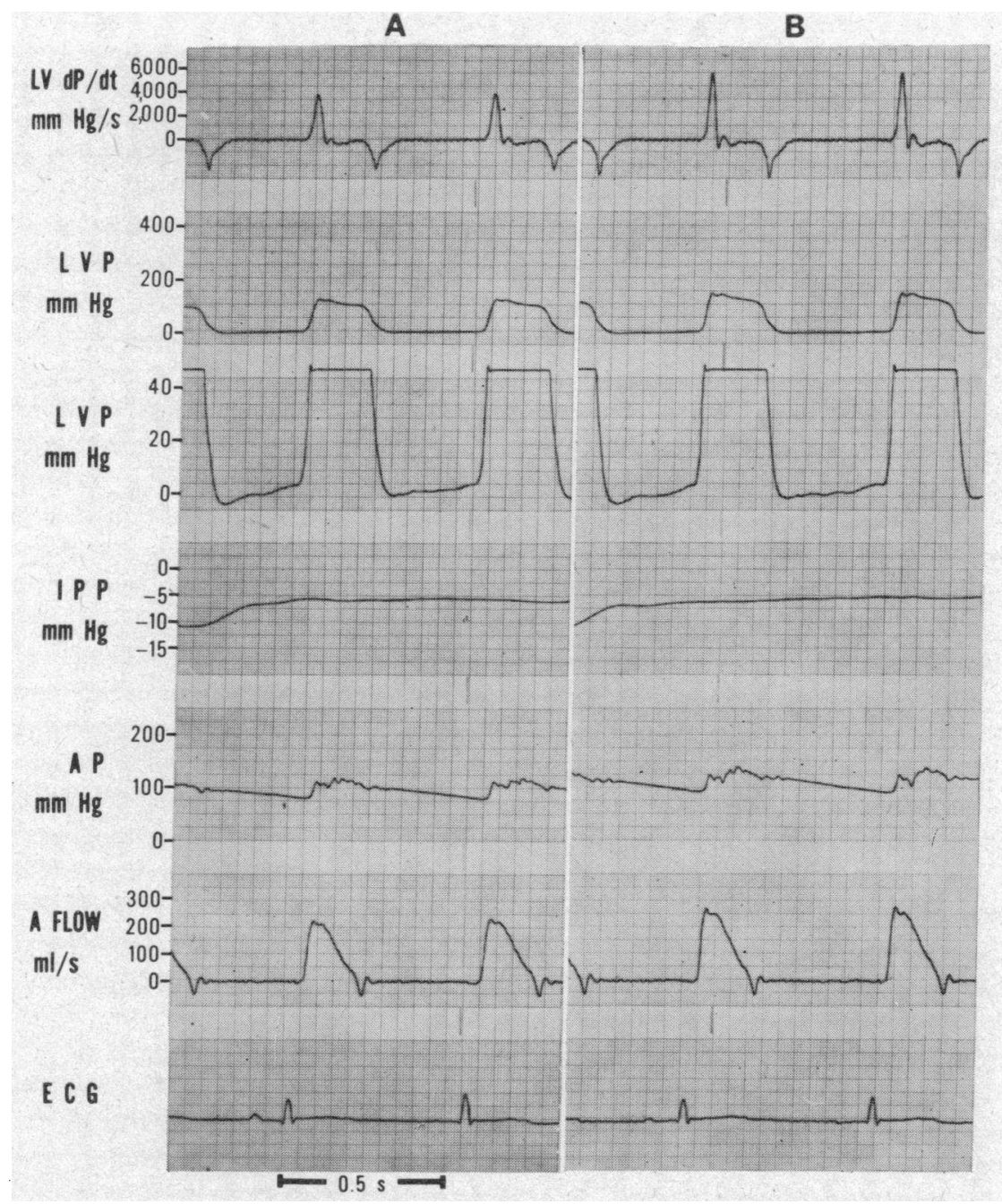

FIGURE 2 Recordings from a normal dog in the control state (panel A) and after acetylstrophanthidin administration (panel B) at comparable phases of respiration. Contrast the unchanged LVEDP with the response in an animal with aortic regurgitation shown in Fig. 1. Abbreviations as in Fig. 1.

inotropic effects, although this does not exclude that elevation of LVEDP may have contributed to the increase in $\mathrm{LV} \mathrm{d} p / \mathrm{d} t$ produced by acetylstrophanthidin in animals with regurgitation. The agents' other cardiovascular effects, the increase in systemic vascular resistance induced by acetylstrophanthidin and the decrease in vascular resistance and tachycardia induced by glucagon, produced contrasting effects upon aortic regurgitation

Regurgitant blood flow measured in this study obviously includes diastolic coronary blood flow. Predictably, coronary blood flow increases in response to glucagon(31-33), so that any error in the measurement of regurgitant flow would have tended to oppose the observed changes, ie., the magnitude of the decrease in aortic regurgitation induced by glucagon would have been, if anything, underestimated. On the other hand, digitalis-induced changes in contractility, LVEDP, and ventricular volume, and in aortic pressure would also increase myocardial oxygen requirements and tend to increase coronary blood flow through the mechanism of autoregulation (34). Direct coronary vasconstriction (9) would tend to counter this, but if the autoregulatory effect predominanted, the increase in aortic regurgitation resulting from acetylstrophanthidin would have been overestimated. This discussion is, however, rather theoretical, since coronary blood flow is so small in relation to aortic regurgitant flow that even major changes in coronary flow would not introduce important errors (14). 
A

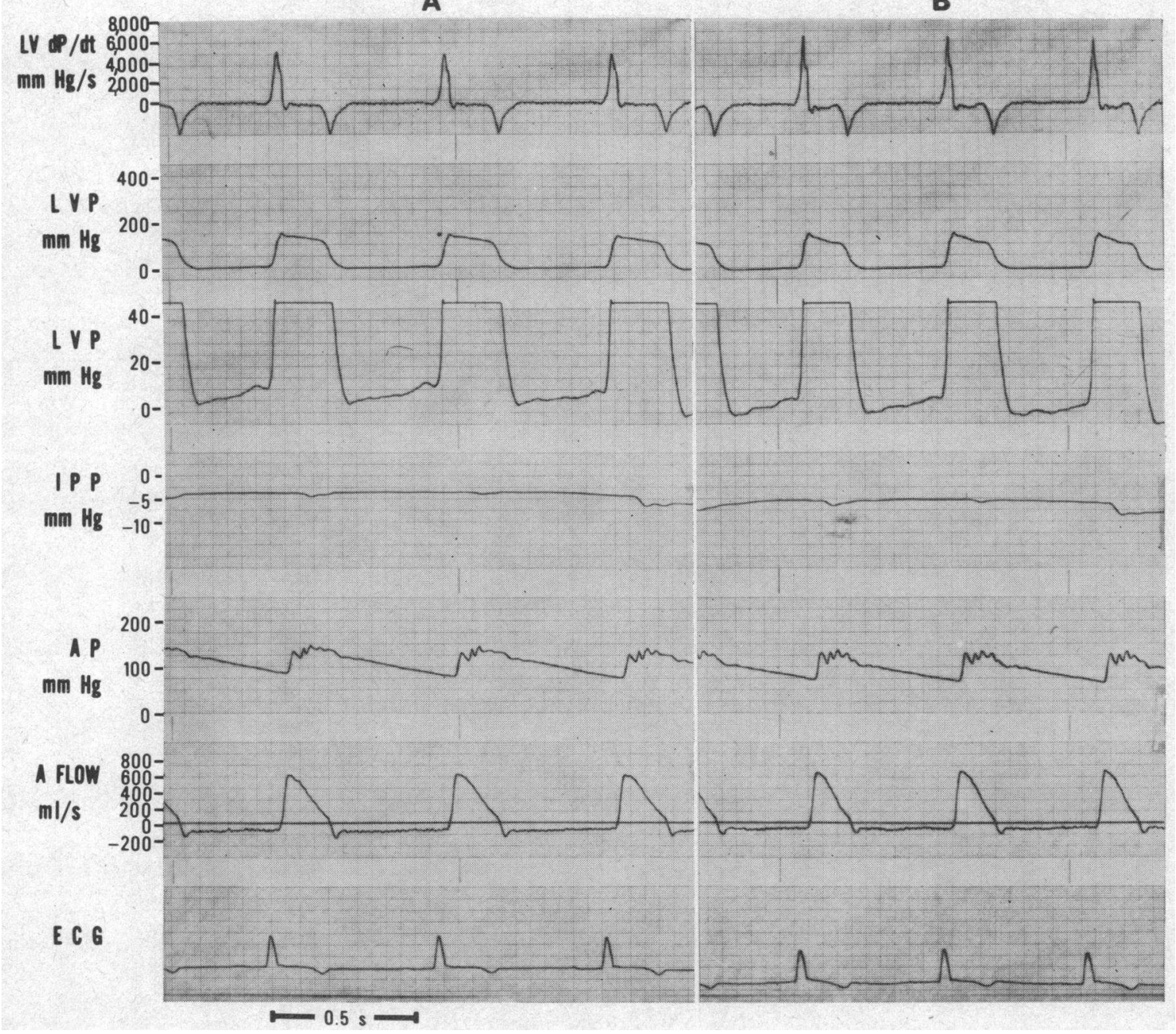

FIGURE 3 Recordings from an animal with aortic regurgitation in the control state (panel A) and after glucagon (panel B) at comparable phases of respiration. Early diastolic regurgitant flow rate in this animal fell from 110 to $60 \mathrm{ml} / \mathrm{s}$, RV from 34 to $21 \mathrm{ml} /$ beat and, although total stroke volume increased from 23 to $28 \mathrm{ml}$, left ventricular end-diastolic pressure (LVP-IPP) fell from 13 to $9 \mathrm{~mm} \mathrm{Hg}$. Abbreviations as in Fig. 1.

The increase in aortic regurgitation produced by acetylstrophanthidin was entirely due to increase in regurgitant flow rate and secondary to increase in aortic pressure and aorto-ventricular diastolic pressure difference, and hence to the increase in systemic vascular resistance $(14,35)$. The decrease in systemic vascular resistance with glucagon was important in producing the relative decrease in regurgitation, but the mechanism is not as simple. Regurgitant flow rate did significantly decrease, but not sufficiently to produce a consistent and significant fall in RV per minute. Ettinger, Frank, and Levinson (36) have suggested that decrease in systemic vascular resistance, per se, may decrease aortic re- gurgitation. Although it is not easy to understand how this factor would operate directly, apart from its influence on aorto-ventricular pressure gradient, perhaps in a dynamic flow situation changes in vascular impedance could exert such a subtle effect. What is clear is that the fall in vascular resistance induced by glucagon preferentially enhanced forward blood flow and that regurgitant flow per minute decreased or remained constant in the face of a large increase in effective cardiac output, the latter effect being due to the integrated response associated with decrease in systemic vascular resistance and increase in myocardial contractility and tachycardia. 
A

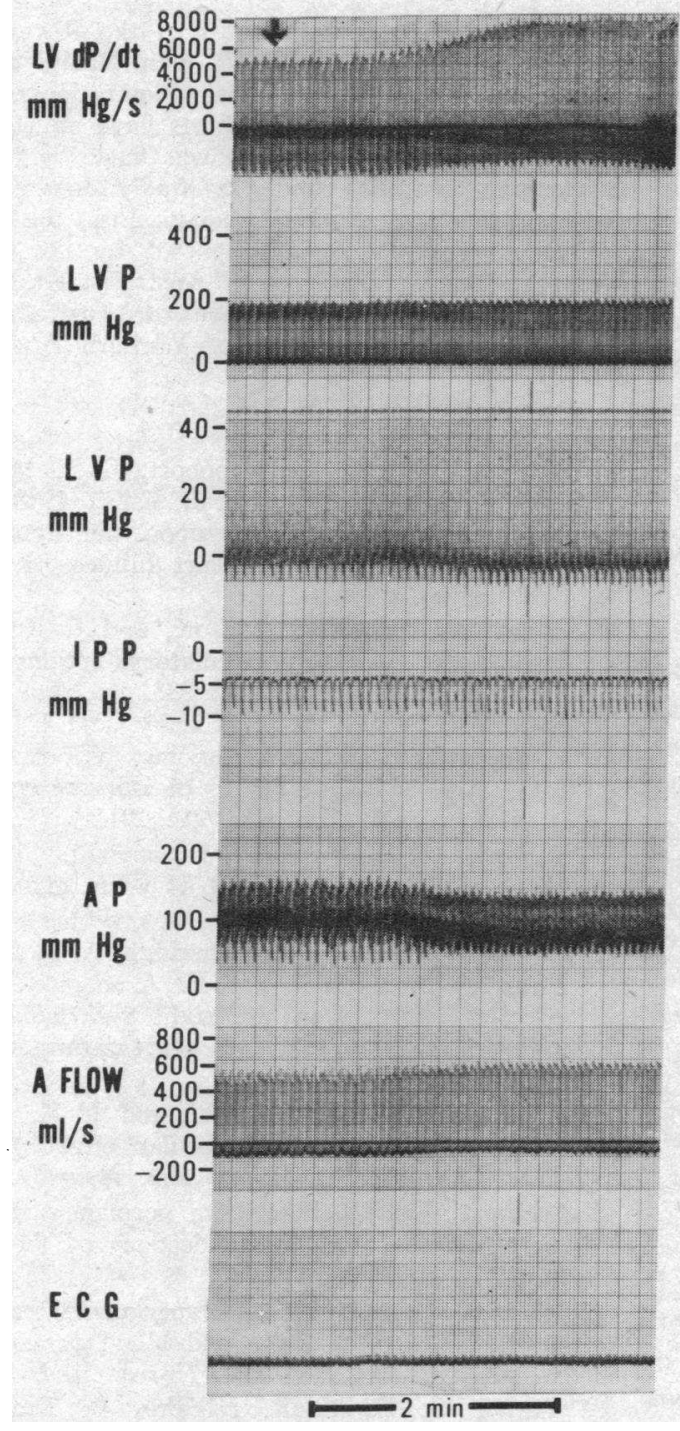

B

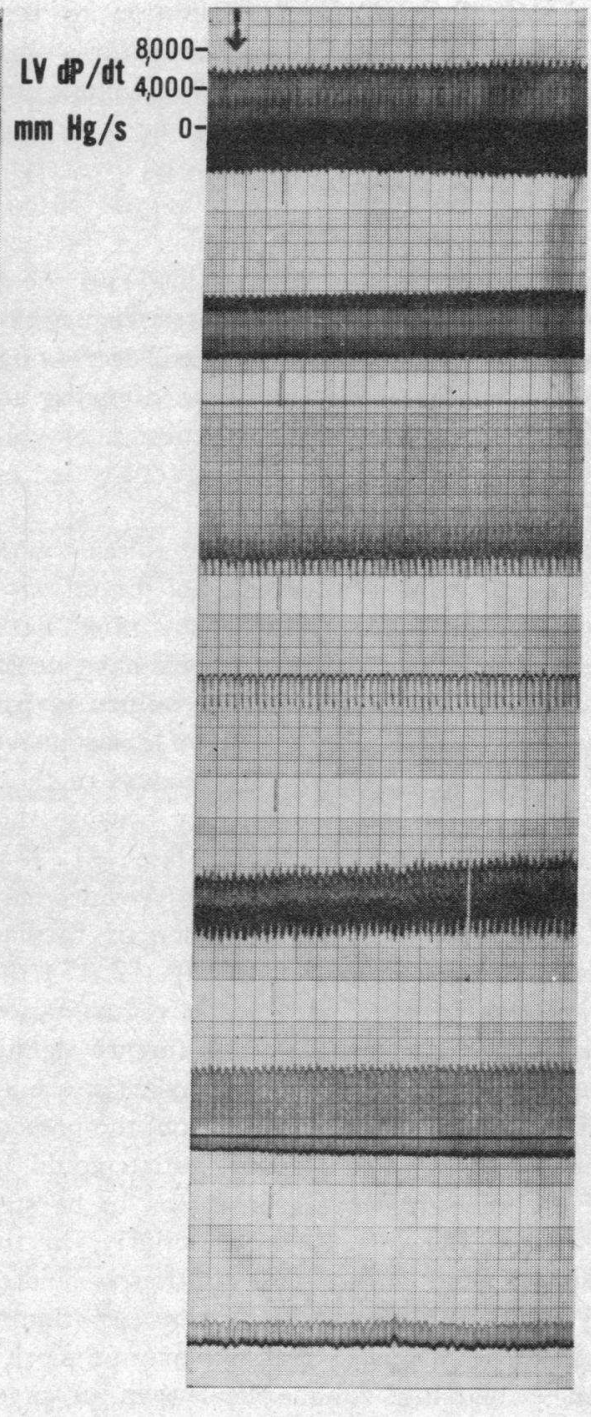

FIGURE 4 Recordings from an animal with aortic regurgitation during the intravenous administration of glucagon $40, \mu \mathrm{g} / \mathrm{kg}$, (panel A) and intravenous ouabain, $20 \mu \mathrm{g} / \mathrm{kg}$, (panel B). Arrows mark commencement of injections. Abbreviations as in Fig. 1. Paper speed $0.5 \mathrm{~mm} / \mathrm{s}$. Note different scales for $\mathrm{LV} \mathrm{d} p / \mathrm{d} t$ in the two panels.

The effect of tachycardia, per se, on aortic regurgitation is complex. Abbreviation of diastole and of regurgitant period per beat regularly decreases RV per beat (16, 37-39), an effect seen with glucagon. RV per minute may or may not decrease with tachycardia, because of accompanying increase in aortic pressure and because shortening of systole may be associated with a negligible decrease in the total duration of diastole per minute $(16,38,39)$. The duration of the regurgitant period per minute was unchanged by glucagon, and hence tachycardia, per se, did not affect regurgitation per minute at all. These factors did not play any role in the increase in regurgitation induced by acetylstrophanthidin, but if sinus bradycardia had occurred, as has been observed to follow digitalis administration in the presence of cardiac failure (10) and during anesthesia (9), it may, if anything, have increased regurgitation further.

In normal animals, acetylstrophanthidin did not change LVEDP, presumably because the increase in left ventricular contractility was just balanced by the increase in aortic pressure and afterload, stroke volume being 
constant. In contrast, LVEDP was increased in animals with aortic regurgitation because, in addition to the above factors being operative, regurgitation was increased, necessitating greater total stroke volume to maintain a constant effective stroke volume, i.e., the volume load on the left ventricle was increased by acetylstrophanthidin in the presence of aortic regurgitation, but was unchanged in the normal animal. In further contrast, glucagon reduced the volume load per beat on the left ventricle in the presence of aortic regurgitation; regurgitant flow per beat was reduced, decreasing total stroke volume while, at the same time, allowing an increase in effective stroke volume. Diminution of volume load and increase in myocardial contractility led to a fall in LVEDP.

While the results of these experiments in animals with relatively acute aortic regurgitation are not directly applicable to the usual clinical situation, they raise some interesting questions. Digitalis preparations have occasionally been found to aggravate cardiac failure in patients with myocardial infarction $(4,6)$ or hypertensive cardiovascular disease (5), presumably because of their vasopressor effect and perhaps particularly because this effect may preceed the inotropic effect $(6,9,11,17)$. Although the vasopressor response to the glycosides may be attenuated or reversed in the presence of cardiac failure, at least in some circumstances, $(10,12,13)$ the effects of digitalis in patients with aortic regurgitation of various clinical types clearly require further definition. For example, concerning the prophylactic use of digitalis in patients with aortic regurgitation, the present experiments indicate that aortic regurgitation could be aggravated if the vasopressor response was to be sustained in the nonfailing circulation. Similarly, in the patient with severe acute aortic regurgitation associated with ruptured aortic cusp, in which situation elevation of LVEDP and pulmonary venous pressure may be more a function of overwhelming volume load than of myocardial failure (15), the place of digitalis glycosides may be open to doubt. While variable and often disappointing results have been obtained with glucagon therapy in patients with severe chronic heart disease (20-25), perhaps because of failure to stimulate the enzyme, adenyl cyclase, in the presence of cardiac failure (26), reports of its use in acute myocardial infarction are generally more optomistic (27-30). In view of these points, the effects observed with glucagon suggest that it and other agents with similar hemodynamic effects, such as isoproterenol, could be useful in the emergency management of acute severe aortic regurgitation. The present study does not claim to answer these questions, but rather, in demonstrating, analyzing, and contrasting the effects of acute digitalisation and glucagon administration on aortic regurgitation in an animal model, serves to propose them.

\section{B. E. Hopkins and R. R. Taylor}

\section{ACKNOWLEDGMENTS}

Mr. C. Henderson and the staff of the Royal Perth Hospital Research Centre, Mr. R. van Raalte and members of the Department of Medical Illustrations, Miss Sheila Wiseman and Miss Tanya Roberts gave valuable assistance in this study. The valvulotome was made by Mr. Ian Jack. Eli Lilly (Australia) and Co. kindly donated the acetylstrophanthidin and Roche Products Ltd., the acetylcholine.

This investigation was supported by the Noel Beaven Heart Foundation of Western Australia, Grant G693 from the National Heart Foundation of Australia and Grant 90.0016 from the University of Western Australia.

\section{REFERENCES}

1. Bloomfield, R. A., B. Rapoport, J. P. Milnor, W. K. Long, J. G. Mebane, and L. B. Ellis. 1948. The effects of the cardiac glycosides upon the dynamics of the circulation in congestive heart failure. I. Ouabain. $J$. Clin. Invest. 27: 588.

2. Braunwald, E., D. T. Mason,, and J. Ross, Jr. 1965. Studies on the cardiocirculatory actions of digitalis. Medicine (Baltimore). 44: 233.

3. Hood, W. B., Jr., B. McCarthy, and B. Lown. 1967. Myocardial infarction following coronary ligation in dogs. Hemodynamic effects of isoproterenol and acetylstrophanthidin. Circ. Res. 21: 191.

4. Karliner, J. S., and E. Braunwald. 1972. Present status of digitalis treatment of acute myocardial infarction. Circulation. 45: 891.

5. Bayliss, R. I. S., M. J. Etheridge, A. L. Hyman, H. G. Kelly, J. McMichael, and E. A. S. Reid. 1950. The effect of digoxin on the right ventricular pressure in hypertensive and ischaemic heart failure. Br. Heart J. $12: 317$.

6. Cohn, J. N., F. E. Tristani, and I. M. Khatri. 1969. Cardiac and peripheral vascular effects of digitalis in clinical cardiogenic shock. Am. Heart J. 78: 318.

7. Corrigan, D. J. 1932. On permanent patency of the mouth of the aorta, or inadequacy of the aortic valves. Med. Surg. $37: 225$.

8. Stewart, H. A. 1908. Experimental and clinical investigation of the pulse and blood pressure changes in aortic insufficiency. Arch. Intern. Med. 1: 102.

9. Vatner, S. F., C. B. Higgins, D. Franklin, and E. Braunwald. 1971. Effects of a digitalis glycoside on coronary and systemic dynamics in conscious dogs. Circ. Res. 28: 470.

10. Higgins, C. B., S. F. Vatner, and E. Braunwald. 1972. Regional hemodynamic effects of a digitalis glycoside in the conscious dog with and without experimental heart failure. Circ. Res. 30: 406.

11. Braunwald, E., R. D. Bloodwell, L. I. Goldberg, and A. G. Morrow. 1961. Studies on digitalis. IV. Observations in man on the effects of digitalis preparations on the contractility of the non-failing heart and on total vascular resistance. J. Clin. Invest. 40: 52.

12. Mason, D. T., and E. Braunwald. 1964. Studies on digitalis. $\mathrm{X}$. Effects of ouabain on forearm vascular resistance and venous tone in normal subjects and in patients with heart failure. J. Clin. Invest. 43: 532.

13. Harvey, R. M., M. I. Ferrer, R. T. Cathcart, D. W. Richards, Jr., and A. Cournand. 1949. Some effects of digoxin upon the heart and circulation in man: digoxin in left ventricular failure. Am. J. Med. 7: 439. 
14. Hopkins, B. E., and R. R. Taylor. 1973. Influence of various catecholamines on aortic regurgitation. $J$. Appl. Physiol. 34 : 309.

15. Taylor, R. R., and B. E. Hopkins. 1972. Left ventricular response to experimentally induced chronic aortic regurgitation. Cardiovasc. Res. 6: 404.

16. Taylor, R. R., and B. E. Hopkins. 1972. Influence of respiration and respiratory sinus arrhythmia on aortic regurgitation. Am. J. Physiol. 223: 668 .

17. Vatner, S. F., C. B. Higgins, T. Patrick, D. Franklin, and E. Braunwald. 1971. Effects of cardiac depression and of anesthesia on the myocardial action of a cardiac glycoside. J. Clin. Invest. 50: 2585.

18. Farah, A., and R. Tuttle. 1960. Studies on the pharmacology of glucagon. J. Pharmacol. Exp. Ther. 129: 49.

19. Lucchesi, B. R. 1968. Cardiac actions of glucagon. Circ. Res. 22: 777.

20. Parmley, W. W., G. Glick, and E. H. Sonnenblick. 1968. Cardiovascular effects of glucagon in man. New Engl. J. Med. 279: 12.

21. Linhart, J. W., S. S. Barold, L. S. Cohen, F. J. Hildner, and P. Samet. 1968. Cardiovascular effects of glucagon in man. Am. J. Cardiol. 22: 706.

22. Williams, J. F., Jr., R. H. Childress, J. N. Chip, and J. F. Border. 1969. Hemodynamic effects of glucagon in patients with heart disease. Circulation. 39: 38.

23. Greenberg, B. H., A. G. Tsakiris, E. A. Moffitt, and R. L. Frye. 1970. The hemodynamic and metabolic effects of glucagon in patients with chronic valvular heart disease. Mayo Clin. Proc. 45: 132.

24. Armstrong, P. W., H. K. Gold, W. M. Daggett, W. G. Austen, and C. A. Sanders. 1972. Hemodynamic evaluation of glucagon in symptomatic heart disease. Circulation. 44: 67.

25. Amsterdam, E. A., R. Zelis, J. F. Spann, Jr., E. J. Hurley, and D. T. Mason. 1970. Cardiocirculatory effects of glucagon in patients with congestive heart failure and cardiogenic shock. Am. J. Cardiol. 25: 82.

26. Gold, H. K., K. H. Prindle, G. S. Levey, and S. E. Epstein. 1970. Effects of experimental heart failure on the capacity of glucagon to augment myocardial contractility and activate adenyl cyclase. J. Clin. Invest. 49: 999.

27. Kones, R. J., and J. H. Phillips. 1971. Glucagon: present status in cardiovascular disease. Clin. Pharmacol. Ther. 12: 427.
28. Puri, P. S., and R. J. Bing. 1969. Effects of glucagon on myocardial contractility and hemodynamics in acute experimental infarction. Basis for its possible use in cardiogenic shock. Am. Heart J. 78: 660 .

29. Diamond, G., J. Forrester, R. Danzig, W. W. Parmley, and H. J. C. Swan. 1971. Haemodynamic effects of glucagon during acute myocardial infarction with left ventricular failure in man. Br. Heart J. 33: 290.

30. Lvoff, R., and D. E. L. Wilcken. 1972. Glucagon in heart failure and in cardiogenic shock. Experience in 50 patients. Circulation. 45: 534.

31. Goldschlager, N., E. Robin, C. M. Cowan, G. Leb., and R. J. Bing. 1969. The effect of glucagon on the coronary circulation in man. Circulation. 40: 829.

32. Bache, R. J., P. A. McHale, C. L. Curry, J. A. Alexander, and J. C. Greenfield. 1970. Coronary and systemic hemodynamic effects of glucagon in the intact unanesthetized dog. J. Appl. Physiol. 29: 769.

33. Manchester, J. H., W. W. Parmley, J. M. Matloff, A. J. Leidtke, P. J. LaRaia, M. V. Herman, E. H. Sonnenblick, and R. Gorlin. 1970. Effects of glucagon on myocardial oxygen consumption and coronary blood flow in man and in dog. Circulation. 41:579.

34. Sonnenblick, E. H., J. Ross, Jr., and E. Braunwald. 1968. Oxygen consumption of the heart. Newer concepts of its multifactorial determination. $\mathrm{Am}$. J. Cardiol. 22: 328.

35. Gorlin, R., I K. R. McMillan, W. E. Medd, M. B. Mathews, and R. Daley. 1955. Dynamics of the circulation in aortic valvular disease. $\mathrm{Am}$. J. Med. 18: 855.

36. Ettinger, P. O., M. J. Frank, and G. E. Levinson. 1972. Hemodynamics at rest and during exercise in combined aortic stenosis and insufficiency. Circulation. $45: 267$.

37. Brawley, R. K., and A. G. Morrow. 1967. Direct determinations of aortic blood flow in patients with aortic regurgitation. Effects of alterations in heart rate, increased ventricular preload or afterload, and isoproterenol. Circulation. 35: 32.

38. Judge, T. P., J. W. Kennedy, L. J. Bennett, R. E. Wills, J. A. Murray, and J. R. Blackmon. 1971. Quantitative hemodynamic effects of heart rate in aortic regurgitation. Circulation. 44: 355.

39. Malooly, D. A., D. E. Donald, H. W. Marshall, and E. H. Wood. 1963. Assessment of an indicator-dilution technic for quantitating aortic regurgitation by electromagnetic flowmeter. Circ. Res. 12: 487. 